АНАТОМО-ФУНКЦИОНАЛЬНАЯ ХАРАКТЕРИСТИКА УРОВНЯ ФИЗИЧЕСКОГО РАЗВИТИЯ И КОМПОНЕНТНЫЙ СОСТАВ ТЕЛА СТУДЕНТОВ ЮНОШЕСКОГО ВОЗРАСТА РЕСПУБЛИКИ МОРДОВИЯ

1Юртайкина М.Н., 2Чаиркин И.Н., ${ }^{3}$ Селякин С.П., ${ }^{1 М и ш е ч к и н ~ М . М ., ~}{ }^{1 Р ы б а к о в ~}$ А.Г., ${ }^{1}$ Паршин А.А., ${ }^{1}$ Кондюрова Е.В.

${ }^{1}$ Национальный исследовательский Мордовский государственный университет имени Н.П. Огарева, Саранск, 2Первый Московский государственный медицинский университет имени И.М. Сеченова, Москва, зЧайковский государственный институт физической культуры, Ижевск, Россия, e-mail: m.n.yurtaikina@rambler.ru

\title{
ANATOMICAL AND FUNCTIONAL CHARACTERISTICS OF THE LEVEL OF PHYSICAL DEVELOPMENT AND THE COMPONENT COMPOSITION OF THE BODY OF STUDENTS IN MORDOVIA REPUBLIC OF YOUTHFUL AGE 1Yurtaykina MN, ${ }^{2}$ Chairkin IN, ${ }^{3}$ Selyakin SP, ${ }^{1}$ Mishechkin MM, ${ }^{1}$ Rybakov AG, ${ }^{1}$ Parshin AA, ${ }^{1}$ Kondyurova EV \\ ${ }^{1}$ Ogarev National Research Mordovia State University, Saransk; ${ }^{2}$ Sechenov First Moscow State Medical University, Moscow; ${ }^{3}$ Tchaikovsky State Institute of Physical Culture, Izhevsk, Russia, e-mail: m.n.yurtaikina@rambler.ru
}

Для ицтирования:

Юртайкина М.Н., Чаиркин И.Н., Селякин С.П., Мишечкин М.М., Рыбаков А.Г., Паршин А.А., Кондюрова Е.В. Анатомофункциональная характеристика уровня физического развития и компонентный состав тела студентов юношеского возраста Республики Мордовия// Морфологические ведомости.- 2020.- Том 28.- № 4.- С. 61-67. https://doi.org/10.20340/mv$m n .2020 .28(4): 430$

For the citation:

Yurtaykina MN, Chairkin IN, Selyakin SP, Mishechkin MM, Rybakov AG, Parshin AA, Kondyurova EV. Anatomical and functional characteristics of the level of physical development and the component composition of the body of students in Mordovia Republic of youthful age. Morfologicheskie Vedomosti - Morphological Newsletter. 2020;28(4):61-67. https://doi.org/10.20340/mv$m n .2020 .28(4): 430$

Резюме. Изучение основных закономерностей формирования физического здоровья студентов имеет большое значение для государства не только как экономического, но и как трудового и оборонного потенциала страны. Изучение возрастной динамики также необходимо для разработки региональных нормативов физического развития, физической подготовленности популяции молодежи, для совершенствования системы здоровье сберегающих технологий при организации и проведении учебного процесса в образовательных учреждениях. Целью исследования явилось изучение уровня физического развития и компонентного состава тела 1612 юношей в возрасте 17-21 года проживающих в Республики Мордовия. В ходе работы было проанализировано 48 абсолютных антропометрических показателей, характеризующих анатомофункциональные особенности индивидуума. Установлено, что среди молодых людей распространен нормостенический тип конституции с пропорциональной грудной клеткой, со средней по форме головой, андроморфного типа телосложения. В популяции лиц юношеского возраста мужского пола характерно преобладание лиц со средним уровнем физического развития, средним значением жизненного индекса, однако, силовой индекс кисти у большинства исследованных имел показатель ниже нормы. У большинства студентов выявлен нормальный показатель массы тела со средним уровнем плотности тела, с повышенной относительной массой жирового и мышечного компонентов и сниженной массой костного компонента, что, возможно, является следствием ответной реакции организма на негативные влияния экологических факторов, а также сниженную двигательную активность и недостаточную физическую нагрузку.

Ключевые слова: физическое развитие, юноческий возраст, юноши, студенты, Республика Мордовия

Summary. The study of the basic laws of the formation of students' physical health is of great importance for the state not only as an economic, but also as a labor and defense potential of the country. The study of age dynamics is necessary also for the development of regional standards of physical development, physical fitness of population of young people, as well as for improving the system of health-saving technologies in the organization and conduct of the educational process in educational institutions. The aim of the study was to study the level of physical development and body composition of 1612 young men aged 17-21 living in the Republic of Mordovia. In the course of the work, 48 absolute anthropometric indicators were analyzed, characterizing the anatomical and functional characteristics of an individual. It was found that among young people a normosthenic type of constitution with a proportional chest, with a medium-sized head and andromorph body type is widespread. In the population of student's males, the prevalence of persons with an average level of physical development, an average value of the vital index is characteristic, however, the strength index of the hand in most of the studied had an indicator below normal. The majority of students showed a normal body mass index with an average level of body density, with an increased relative mass of fat and muscle components and a reduced mass of the bone component, which is possibly a consequence of the body's response to the negative influences of environmental factors, as well as reduced motor activity and insufficient physical activity.

Key words: physical development, adolescence, young men, students, Republic Mordovia 
Введение. Студенческая молодежь представляет особую социальную группу, объединенную определенным возрастом, специфическим условиями жизни, учебы и труда. Проблема состояния здоровья студентов высших учебных заведений в настоящее время находится в сфере особого внимания государства [1]. Изучение основных закономерностей формирования физического здоровья детей, школьников и студентов имеет большое значение для государства не только в качестве экономического, но и трудового и оборонного потенциала страны [2-9]. Следовательно, главное внимание в решении этой проблемы должно приходиться на контроль физического развития и состояние здоровья лиц юношеского возраста, так как в этом возрасте происходит завершение формирования отдельных анатомических структур организма, а также формирование его соматотипа, и поэтому этот период является определяющим для здоровья поколения в целом [10-11]. Изучение возрастной динамики также необходимо для разработки региональных нормативов физического развития, физической подготовленности молодежи, для совершенствования системы здоровье сберегающих технологий при организации и проведении учебного процесса в образовательных учреждениях [12-13].

Цель исследования: изучить антропометрические показатели, компонентный состав тела и основные показатели физического развития юношей-студентов Республики Мордовия в возрасте от 17 лет до 21 года.

Материалы и методы исследования. Материалом исследования послужили результаты обследования 1612 юношей-студентов в возрасте от 17 лет до 21 года, обучающихся в Национальном исследовательском Мордовском государственном университете имени Н.П. Огарева (г. Саранск). Выбор методов исследования определялся их безопасностью, информативностью и неинвазивностью в соответствии с поставленной целью и задачами работы. Исследование проводилось с соблюдением принципов добровольности, прав и свобод личности, гарантированных статьями 21 и 22 Конституции Российской Федерации. Для проведения исследования был разработан специальный протокол письменного согласия студента, принимающего участие в антропометрическом исследовании. Из опасения привнести в полученные результаты заметные этнотерриториальные отличия, в исследовании участвовали только те молодые люди, чьи предки и родители по этнической принадлежности относятся к славянам, по национальности относятся к этнической мордве и русским. Антропометрическое исследование было проведено по методу Бунака (1941) с использованием стандартного набора антропометрических инструментов [14]. В ходе работы нами было проанализировано 48 абсолютных антропометрических показателей, характеризующих анатомо-функциональные особенности индивидуума. Для оценки полученных результатов антропометрических величин и выявления региональных особенностей физического развития студенческой молодежи Республики Мордовия по антропометрическим показателям были рассчитаны индекс Ретциуса, индекс Кетле II, индекс Пирке (Бедузе), индекс Рорера, индекс Эрисмана, индекс Таннера и показатель экскурсии грудной клетки. По формуле Изаксона находили площадь поверхности тела. По стандартным формулам Матейки производили расчеты абсолютных и относительных величин жирового, мышечного и костного компонентов тела. Функциональные показатели юношей-студентов изучались общепринятыми методами функциональной диагностики, такими как динамометрия и спирометрия. Рассчитывались показатели жизненного индекса и силового индекса. Соматотипирование проводилось по результатам определения индекса РисАйзенка. Полученные данные обработаны стандартными методами вариационной статистики. Для проверки нормальности распределения был использован критерий Шапиро-Уилкса. Полученные результаты представлены как $\mathrm{M} \pm \delta$.

Результаты исследования и обсуждение. Результаты проведенного исследования показали, что длина тела в популяции студенческой молодежи юношеского возраста

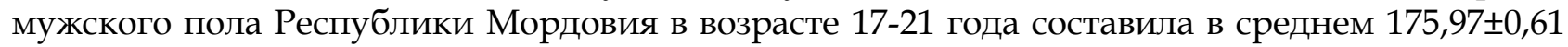

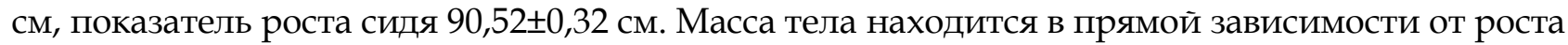
тела и при оценке физического развития является одним из основных и весьма лабильных 
показателей быстро реагирующих и изменяющихся под влиянием различных экзогенных и эндогенных факторов [15]. Масса тела юношей Мордовии в среднем составила 75,76 1,19 кг. Результаты исследования средних продольных и поперечных диаметров головы в данной

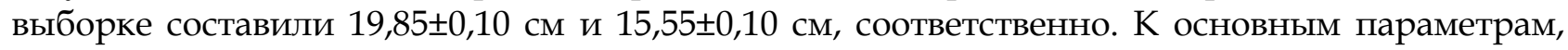
характеризующим общее физическое развитие юноше относят ширину плеч. Изучая средние продольные и поперечные диаметры тела, авторы выявили, что ширина плеч в

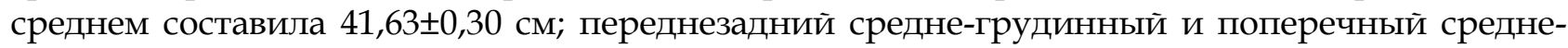

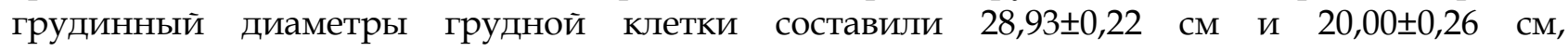

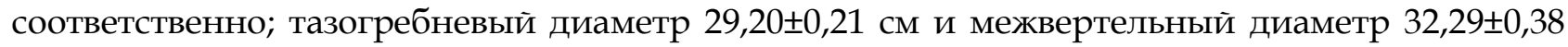
CM.

При измерении охватных размеров тела в исследуемой группе выявлено, что средняя окружность головы составляет 57,22 0,15 см, окружность талии $81,11 \pm 0,97$ см. Наибольшее значение коэффициента вариации в выборке было обнаружено у показателей массы тела $(\mathrm{CV}=15,86 \%)$ и переднезаднего средне-грудинного диаметра (CV=13,32\%). Наименьшей вариабельностью отличились показатели окружности головы $(\mathrm{CV}=2,64 \%)$ и длины тела $(\mathrm{CV}=3,46 \%)$.

При измерении антропометрических параметров длины верхней конечности

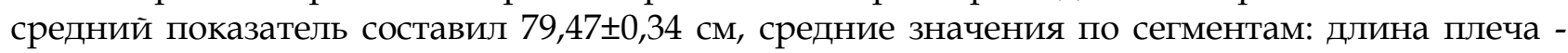

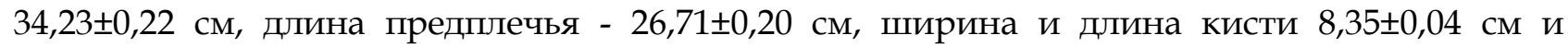
$18,69 \pm 0,08$ см, соответственно. Средний показатель антропометрических величин длины нижней конечности был равен 91,36 $\pm 0,42$ см, и по сегментам соответственно: длина бедра -

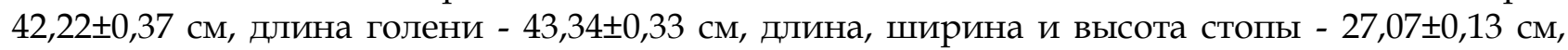

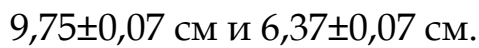

Для более полной характеристики костного компонента сомы популяции студенческой молодежи юношеского возраста мужского пола Республики Мордовия при исследовании диаметров дистальных отделов сегментов конечностей было установлено, что

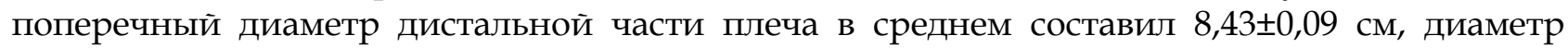

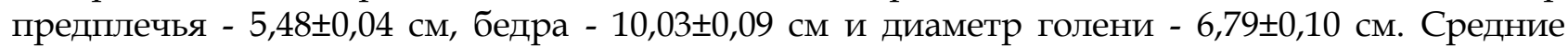
показатели измерений окружностей конечностей составили: окружность плеча

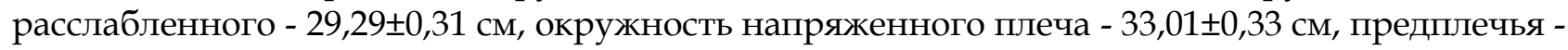

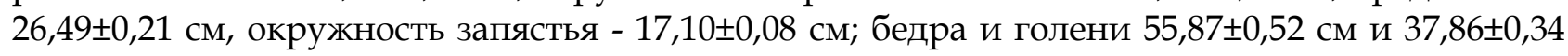
см, соответственно. Наименьшую вариабельность имели показатели длины стопы $(\mathrm{CV}=4,80 \%)$ и окружности запястья $(\mathrm{CV}=5,50 \%)$. Наибольшее значение коэффициента вариации показателя обнаружено у показателя поперечного диаметра дистальной части голени $(\mathrm{CV}=14,55)$.

Изучение компонентного состава тела подразумевает изучение степени выраженности жирового, мышечного, и костного компонентов сомы. Толщину кожножировых складок (далее - КЖС) измеряли для установления компонентного состава тела. Средний показатель толщины КЖС на спине в области нижнего угла лопатки составил

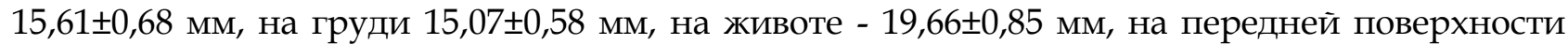

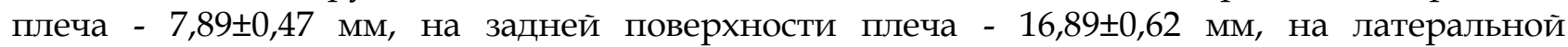

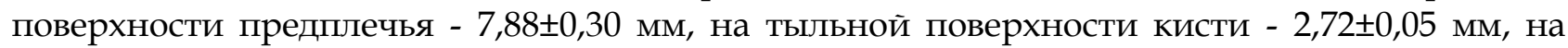

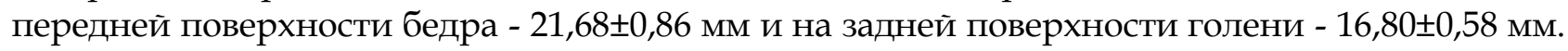
Все показатели КЖС имели высокие значения коэффициента вариации.

При изучении параметров, характеризующих функциональное состояние студенческой молодежи юношеского возраста мужского пола Республики Мордовия,

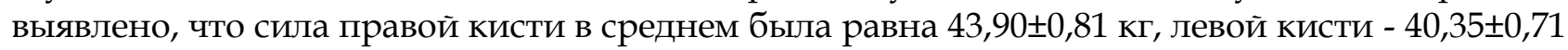

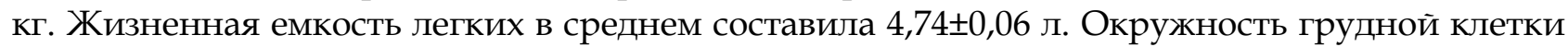

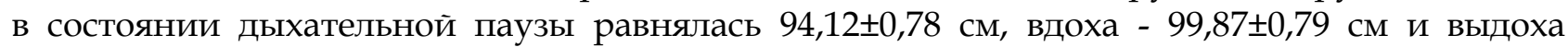
$83,86 \pm 0,45$ см, соответственно. Наибольшее значение коэффициента вариации отмечено у показателя силы левой кисти (CV=18,08\%). Наименьшую вариабельность имел показатель окружности грудной клетки во время вдоха $(\mathrm{CV}=8,11 \%)$. 
Исследование антропометрических показателей, которые характеризуют отдельные сегменты тела и конечностей, а также индексы показателей пропорций телосложения изучаются отдельными исследователями как более точные антропометрические характеристики [16-17]. Несмотря на это, широко апробированные интегральные индексы для оценки физического развития и здоровья в период роста организма на основе общих антропометрических измерений и методов позволяют оценить особенности физического развития отдельных популяций в целом. Они дают возможность оценить как уровень физического развития, так и состояние адаптации детей, подростков и молодежи студенческого возраста к воздействию факторов среды, включая показатели репродуктивного здоровья [3, 5, 7-9]. Для выявления региональных особенностей физического развития молодых людей Республики Мордовия из полученных результатов исследования рассчитывали ряд показателей и антропометрических индексов.

По результатам вычисления головного указателя или индекса Ретциуса в

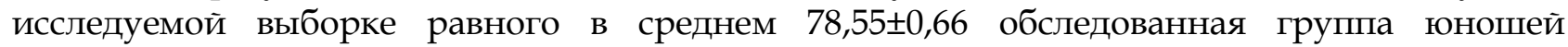
распределилась следующим образом: среднеголовость (мезоцефалия) наблюдалась у 35,58\%, длинноголовость (долихоцефалия) выявлена в $34,62 \%$ случаев, короткоголовость (брахицефалия) у 29,47\% исследуемых. Среднее значение индекса Кетле II составило

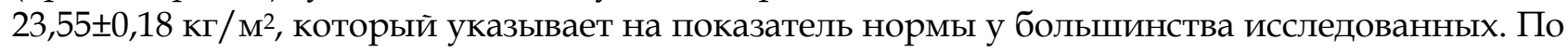
результатам исследования этого индекса нормальный показатель массы тела выявлен в 67,31\% случаев, предожирение отмечено в 28,85\% и дефицит массы тела в 3,85\% случаев.

По результатам определения индекса Рорера в исследуемой группе студентов

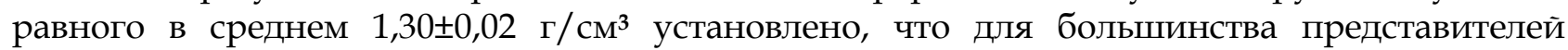
мужской выборки характерен средний уровень плотности тела, отмеченный в 42,31\% случаев, уровень плотности выше среднего находили в 40,38\% случаев, уровень плотности ниже среднего выявлен у 17,31\% обследованных юношей.

Для характеристики пропорциональности физического развития юношей вычисляли

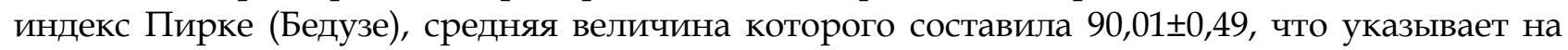
пропорциональность телосложения у большинства исследованных студентов, которое составляет $38,41 \%$ случаев, удлинение конечностей отмечено в $37,80 \%$ случаев и укороченные конечности выявлены у 23,78\% обследованных.

Средний показатель индекса Эрисмана в изученной группе студентов составил $5,81 \pm 0,76$, что указывает на пропорциональное развитие грудной клетки у болышинства исследованных. Среди студенческой молодежи юношеского возраста мужского пола Республики Мордовия индивиды с пропорциональным развитием грудной клетки составили 51,92\%, широкая грудная клетка была характерна для 38,46\% и только в 9,62\% случаев выявлено узкогрудность.

С помощью индекса Таннера или индекса полового диморфизма определяли степень

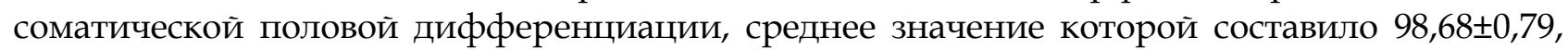
указывая на преобладание ширины плеч над шириной таза. По результатам вычисления индекса выявили, что в популяции юношей-студентов Республики Мордовия в 74,29\% случаев соматический определялся андроморфный тип, в 23,81\% случаев мезоморфный и 1,90\% случаев всей выборки соответствовал гинекоморфному морфотипу (рис. 1). Средний показатель площади поверхности тела среди представителей изучаемой популяции

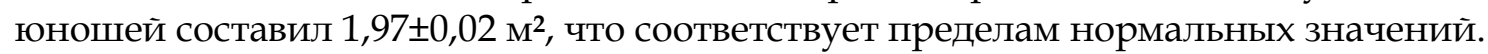

По результатам определения показателя экскурсии грудной клетки, равной в среднем 9,92士0,25 см, обследованная группа распределилась следующим образом. Средний уровень физического развития выявлен в 57,14\% случаев, высокий уровень физического развития был характерен для 41,90\% юношей и низкий уровень выявлен только у 0,95\%

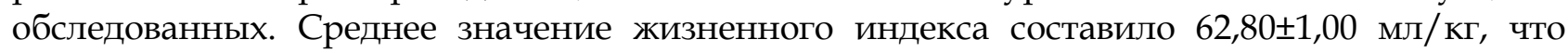
указывает на показатель нормы у большинства представителей изучаемой выборки. По результатам вычисления силового индекса (рис. 2) исследуемой группы студентов среднее

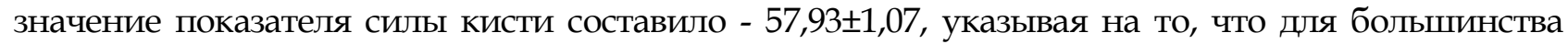
юношей характерен низкий показатель силы кисти. Низкие значения показателя характерны 
для 76,19\% случаев, средние значения показателя для 21,9\% случаев, высокий показатель силы кисти выявлен только у 1,90\% обследованных студентов.

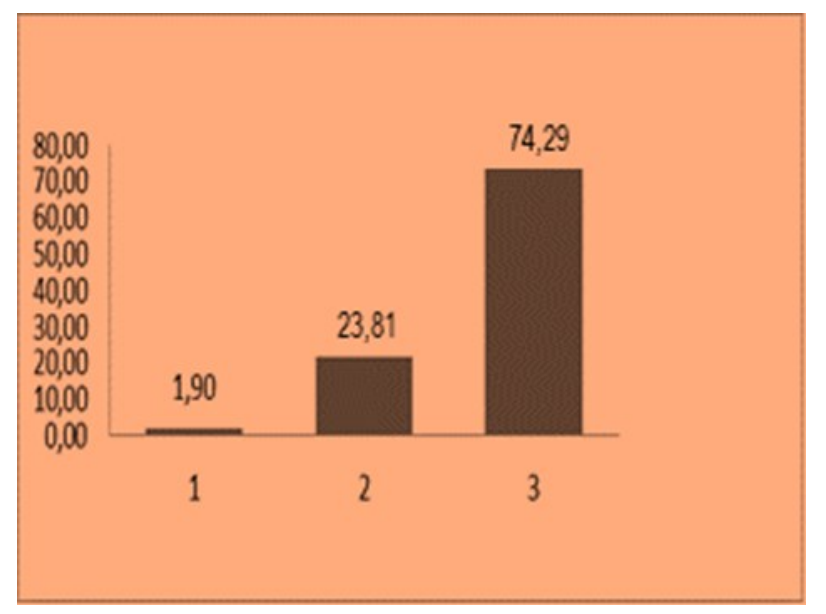

Рис. 1. Распределение популяции студентов-юношей по индексу Таннера. Обозначения: 1 - гинекоморфный тип; 2 мезомор-фный тип; 3 - андроморфный тип.

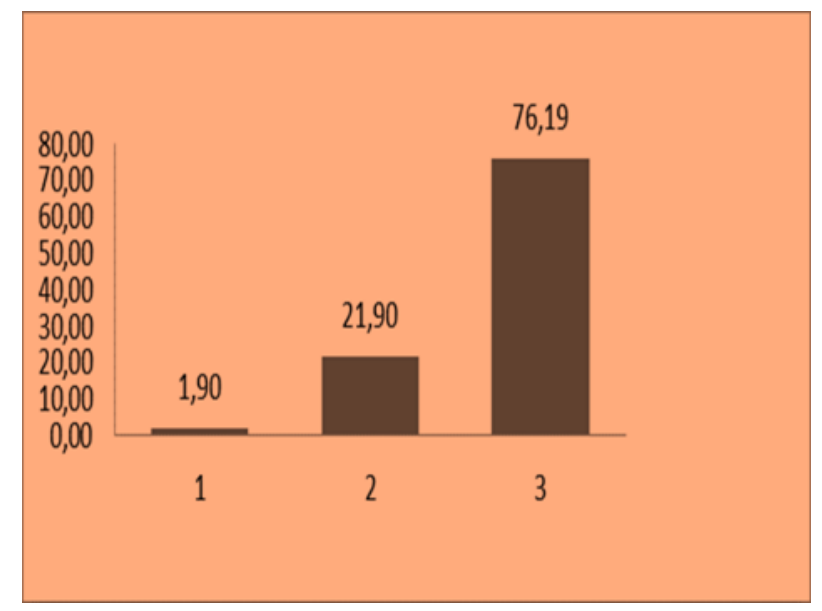

Рис. 2. Распределение популяции студентовюношей по силовому индексу. Обозначения: 1 - высокие значения, 2 - средние значения, 3 - низкие значения.

Для полной характеристики антропометрического портрета студенческой молодежи мужского пола Республики Мордовия производилась оценка абсолютного и относительного количества жирового, мышечного и костного компонента состава тела по стандартным формулам Матейки. В исследованной выборке студенческой молодежи мужского пола юношеского возраста Республики Мордовии среднее значение абсолютной массы жирового

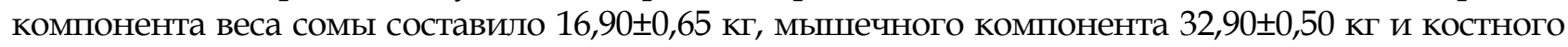
$12,85 \pm 0,18$ кг.

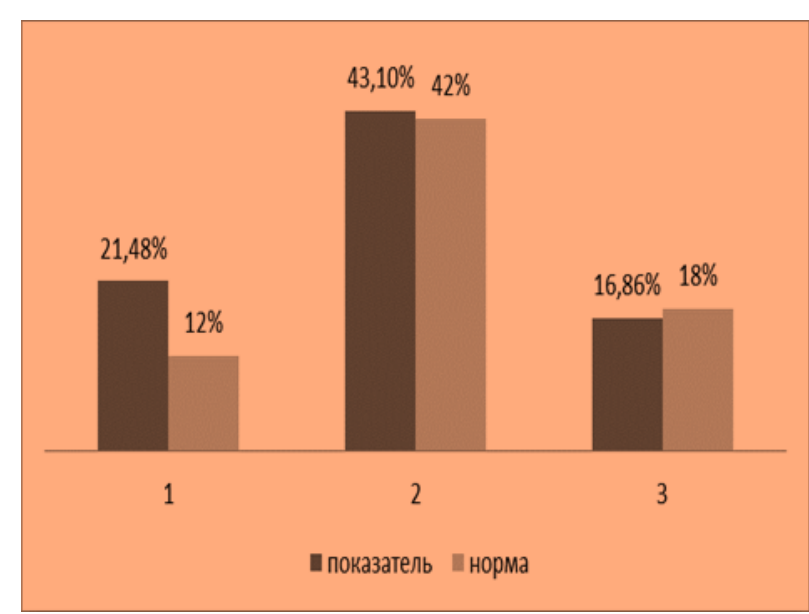

Рис. 3. Показатели состава тела студентовюношей в сравнении с критериями пропорций относительной популяционной нормы. Обозначения: 1 - жировой компонент; 2 мы-шечный компонент; 3 - костный компонент.
Средняя величина относительной массы жирового компонента составила в

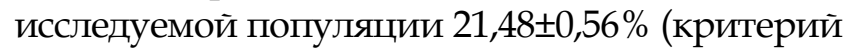
относительной популяционной нормы - 12\%),

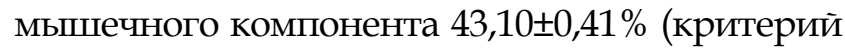
относительной популяционной нормы - 42\%)

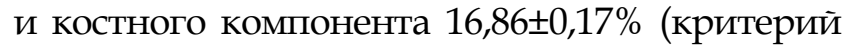
относительной популяционной нормы - 18\%), (рис. 3). Показателем, отражающим уровень и гармоничность развития организма и его функциональный статус, а также общего здоровья является состояние костной ткани. Недостаточность костной массы к 18-20 годам влечет повышенную частоту переломов, которые могут возникать и в более поздние сроки жизни [18]. Некоторыми экспериментальными исследованиями доказано, что конкретные факторы среды могут модулировать и модифицировать морфогенез в конечном итоге определяя окончательные структурно-функциональные особенности

отдельных органов и систем [19]. Обладая высокой пластичностью костная ткань реагирует на изменения двигательной активности и физических нагрузок [20], а также является важным показателем типологических проявлений адаптации. Дальнейшее изучение изменчивости 
костного компонента сомы может способствовать выяснению общих закономерностей взаимодействия организма с окружающей средой и эффективности реализации генотипа в фенотипе [15]. При соматотипировании изученной популяции по результатам индекса РисАйзенка было установлено, что средний показатель равен $103,83 \pm 0,54$. Нормостенический соматотип определялся в 48,57\% случаев, астенический в 40,00\% и пикнический в 11,43\% случаев.

Заключение. Таким образом, анализируя полученные результаты исследования следует отметить, что представители студенческой молодежи юношеского возраста мужского пола Республики Мордовия в большинстве случаев имеют нормостенический тип конституции, обладают андроморфным типом телосложения, отсутствием у большинства излишней массы тела, пропорциональным развитием грудной клетки, средним уровнем физического развития со средней плотностью тела и повышенной массой жирового и мышечного компонентов, сниженной массой костного компонента, что возможно, является ответной реакцией организма на внешние воздействия. В целом для изученной популяции характерно преобладание индивидуумов со средней по форме головой. Среднее значение жизненного индекса у большинства представителей выборки соответствовал показателю нормы. Силовой индекс кисти был ниже нормы у большинства исследованных юношейстудентов, что, по-видимому, может быть связано со слабой физической подготовкой, и на что следует обратить внимание в процессе обучения студентов в университете. Полученные результаты исследования могут быть использованы для построения региональных нормативов физического развития юношей Республики Мордовия, а также при разработке вузовских и региональных оздоровительных программ.

Авторы заявляют об отсутствии каких-либо конфликтов интересов при
планировании, выполнении, финансировании и использовании результатов
настоящего исследования.

\section{Литература \\ References}

1. Sukhanova IV. Somatophysiological characteristics of the physical development of young men in the North-East of Russia: Diss. Cand. biol. Sciences. Magadan, 2007. 147pp.

2. Krikun E.N., Nikityuk D.B., Klochkova S.V., Khayrullin R.M. Osobennosti fizicheskogo razvitiya novorozhdennykh detey Tsentral'no-chernozemnogo rayona Rossii. Voprosy pitaniya. 2014;83(S3):43.

3. Ermolaeva S.V., Khayrullin R.M. Sravnitel'nyy analiz fizicheskogo razvitiya shkol'nikov Ul'yanovskoy oblasti, prozhivayushchikh $v$ rayonakh s razlichnymi ekologicheskimi $i$ sotsial'no-ekonomicheskimi pokazatelyami. Vestnik Moskovskogo universiteta. Seriya 23: Antropologiya. 2015;2:72-81.

4. Galkina T.N. Antropometricheskie i somatotipologicheskie osobennosti lits yunosheskogo vozrasta $v$ Penzenskom regione. Res. of Diss. Cand. med. Science. Volgograd, 2008. 22s.

5. Khayrullin R.M., Ragozina O.V., Astakhov O.B., Ragozin O.N., Khramov E.V. Patterny konstitutsional'nykh osobennostey kak osnova dlya otsenki adaptatsii $k$ uchebnomu protsessu. $V$ sb.: Bioupravlenie v meditsine i sporte. Materialy I Vserossiyskoy konferentsii. 1999. S. 125-126.

6. Gorshenyova EB, Toshnazarov DR, Siddikov UB. A comparative assessment of the physical development of students of medical institutes at Derzhavin Tambov State University and the Kyrgyz-Russian Slavic University. Vestnik TGU. 2017;22(2):279-281.

7. Khayrullin P.M., Tikhonov D.A., Mirin A.A., Svitaylo M.P. Anatomo-antropologicheskie pokazateli fizicheskogo razvitiya i reproduktivnogo zdorov' ya yunoshey. Morfologiya. 2009;136(4):146a.

8. Gur'eva A.B. Zakonomernosti izmenchivosti anatomicheskogo stroeniya tela zhenskogo naseleniya Respubliki Sakha (Yakutiya). Res. of Diss. Doct. med. Science. Krasnoyarsk, 2019. 43pp.

9. Mirina M.P., Khayrullin R.M., Svitaylo A.P., Khamidullina T.S. Issledovanie antropometricheskikh prediktorov prolapsa mitral" 'nogo klapana u lits yunosheskogo vozrasta. Fundamental' nye issledovaniya. 2014. № 7-1. S. 124-128.

10. Afanasievskaya YuS. Anthropometric parameters and the distribution of somatotypes in young people of the Krasnodar region: Diss. Cand. med. Science. Volgograd, 2011. 158pp. 
11. Chairkin IN, Yurtaikina MN, Parshin AA, Mishechkin MM, Chairkina NV, Grishunina KV. Anthropometric characteristic of students from Saransk and Mordovia Republic. Morfologicheskie Vedomosti - Morphological Newsletter. 2015;4:32-37.

12. Kolokoltsev MM, Lebedinsky VYu. Comparative characteristics of the level of physical development of students of youth of the Irkutsk region. Bulletin of the All-Russian Scientific Center of Scientific Sciences of the Russian Academy of Medical Sciences. 2012;6(88):47-54.

13. Timoshenko KT, Nikolenko VN, Minnibaev TSh, Nikityuk DB, Klochkova SV. Anthropometric indicators of young students at the initial stage of training. Health of the population and the environment. 2016;6(279):29-32.

14. Bunak VV. Anthropometry. Moscow: Uchpedgiz, 1941. 368pp.

15. Sidorova TA. Features of adaptive reactions in students in urban environments: Diss. Cand. biol. Sciences. Omsk, 2015. 130pp.

16. Khaǐrullin R. 19. Segmental 2:4 Digit ratio. Unilateral, bilateral and hand-type differences in men. HOMO - Journal of Comparative Human Biology. 2011;62(6): 478-486.

17. Khayrullin R.M., Filippova E.N., Butov A.A., Kasterina A.V., Khayrullin F.R., Zerkalova Yu.F. Lineynye zavisimosti znacheniy pal'tsevogo (2D:4D) indeksa u lits muzhskogo pola. Vestnik Moskovskogo universiteta. Seriya 23: Antropologiya. 2011;2:16-24.

18. Dragich OA. Patterns of morphological and functional variability of the body of juvenile judges in the conditions of the Ural Federal District: Diss. Doct. biol. Sciences. Tyumen, 2006. 298pp.

19. Drozhdina E.P., Sych V.F., Khayrullin R.M., Slesarev S.M. O vliyanii dlitel'nogo potrebleniya dispergirovannoy pishchi na morfogenez myshechnoy obolochki obodochnoy kishki belykh krys. Morfologicheskie vedomosti. 2006;1-2:21-23.

20. Chaplygina EV, Sokolov VV, Bondin VI, Sokolova NG, Elizarova ES. Comparative characteristics of somatometric indicators of girls in the city of Rostov-on-Don and the city of Saratov. Vestnik Morphologii. 2010;16(2):435-437.

\section{Авторская справка}

Юртайкина Мария Николаевна, ассистент, кафедра нормальной и патологической анатомии с курсом судебной медицины, Национальный исследовательский Мордовский государственный университет имени Н.П. Огарева, Саранск, Россия; e-mail: m.n.yurtaikina@rambler.ru

Чаиркин Иван Николаевич, доктор медицинских наук, профессор, кафедра анатомии человека, Первый Московский государственный медицинский университет имени И.М. Сеченова, Москва, Россия; e-mail: chairkin@rambler.ru

Селякин Сергей Петрович, доктор медицинских наук, профессор, кафедра адаптивной физической культуры и оздоровительных технологий, Чайковский государственный институт физической культуры, Ижевск, Россия; e-mail: sselakin@gmail.com

Мишечкин Максим Михайлович, старший преподаватель, кафедра нормальной и патологической анатомии с курсом судебной медицины, Национальный исследовательский Мордовский государственный университет имени Н.П. Огарева, Саранск, Россия; e-mail: maximm-m-m@yandex.ru

Рыбаков Алексей Геннадьевич, кандидат медицинских наук, доцент, заведующий кафедрой, кафедра нормальной и патологической анатомии с курсом судебной медицины, Национальный исследовательский Мордовский государственный университет имени Н.П. Огарева, Саранск, Россия; e-mail: inform13med@yandex.ru

Паршин Александр Александрович, кандидат биологических наук, доцент, кафедра нормальной и патологической анатомии с курсом судебной медицины, Национальный исследовательский Мордовский государственный университет имени Н.П. Огарева, Саранск, Россия; e-mail: phenol107@yandex.ru

Кондюрова Евгения Викторовна, кандидат медицинских наук, доцент, кафедра стоматологии, заведующая кафедрой, Национальный исследовательский Мордовский государственный университет имени Н.П. Огарева, Саранск, Россия; e-mail: evva1342@mail.ru 